\section{Nuclear installations and childhood leukaemia}

SIR-Forman et al. ${ }^{1}$ assert that on present knowledge it is difficult to attribute their findings of a raised incidence of child leukaemia around nuclear installations to ionizing radiation. This conclusion is based on the premises that leukaemia risk per unit dose has not been underestimated and that computed population doses are far too low to account for the increase. Both assumptions are widely held among cancer epidemiologists and radiobiologists, but remain open to question.

In the case of Sellafield, the dose calculations of the National Radiological Protection Board (NRPB) were characterized by profound uncertainties, particularly in the case of alpha-emitters such as $\mathrm{Pu}$ and $\mathrm{Am}^{3,4}$. The dosimetric models were essentially those recommended in ICRP30 (International Commission on Radiological Protection) for adult workers ${ }^{5}$. For children and the fetus the NRPB made rudimentary alterations to take into account physiological rather than metabolic changes, essentially changes in organ dimension and mass ${ }^{6,7}$. ICRP 30 states clearly: "The Commission does not recommend the use of the data and models described in this report to estimate committed dose equivalent to members of a population, for example from radionuclides in the environment, by adjusting solely on the basis of differences in mass of organs or magnitude of intake" " Yet, because of the uncertainties, this is precisely what the NRPB was in large measure forced to do.

Consequently, dose and therefore risk was taken to decrease in reciprocal relation to the rapidly growing body of the fetus and young child. For an alphaemitter lodged in the skeleton, tissue mass is relatively unimportant, and at the cellular level alpha-dose averaged throughout the tissue appears biologically almost meaningless. To calculate the risks of alpha-induced leukaemia it would be necessary to know the exact location of leukaemogenic cells, yet this information is simply not known'. For example, lymphatic leukaemia has not been induced in the lungs of dogs or mice, but it has in rats; Sir Edward Pochin of the NRPB has remarked in this regard: "I do not know whether we are closer to the dog, the mouse, or the rat in terms of lymph-node behaviour"10.

Risk factors are similarly disputed, and the study ${ }^{11}$ cited by Forman et al. in support of their conclusions is but one contribution to an extensive controversy over this question. Uncertainty over alpha dose-response is particularly acute ${ }^{12}$.

Because there is judgement as well as technical evaluation of the data, it is inevitable that there will be dissent from the values put forward; there is no evidence to disprove the ICRP risk factors, but neither is there evidence to verify them ${ }^{13}$.

Given that the pattern of child lymphatic leukaemia around nuclear installations is most unlikely to have occurred by chance, that it could indeed have been caused by ionizing radiation, and that we know of no other likely cause, it would seem at least prudent to give the benefit of the doubt to the local populace, and not, as it has been, to the nuclear industry.

Science Policy Research Unit,

David CROUCH

University of Sussex

Falmer, Brighton,

East Sussex BNI 9RF, UK

1. Forman, D. et al. Nature 329, 499-505 (1987).

The Risks of Leukaemia and Other Cancers in Seascale from Radiation Exposure NRPB-R171 (NRPB, Didcot, 1984).

3. Crouch, D. Sci. Total Envir. 53, 201-216 (1986)

4. Crouch, D. in Radiation and Health (eds Russell Jones, R \& Southwood, R.) 47-63 (Wiley, Chichester, 1987).

Limits on Intakes of Radionuclides by Workers ICRP No. 30, parts 1-3 (ICRP, Geneva, 1979-81)

6. Adams, D Phys med Biol. 26, 1019-1034 (1981)

7. Adams, D. \& Stather, J.W. Radiol. Prot. Bull. 58, 31-36 (1984)

8. Mole, R.H. J. Br. nucl. Energy Soc. 15, 203-213 (1976)

9. Cutler, J. Lancet i, 1161 (1984).

10. Pochin, E.E. Sizewell Inquiry Transcripts Day 151, 101 (1983).

11. Darby, S.C. \& Doll, R. Br. med. J. 294, 603-607 (1987)

12. Charles, M.W. \& Linjdop, P.J. J. Soc. radiol. Prot. 1, 15 19 (1981)

13. Reissland, J.A. J. Soc. radiol. Prot. 3, 28-33 (1983).

\section{Why cystic fibrosis is on the increase}

SiR-In a recent News and Views article, Rotter and Diamond' ${ }^{1}$ described four principles by which recessive alleles responsible for inherited diseases may be maintained at high frequencies. The most common deleterious recessive among Europeans, that which causes cystic fibrosis (CF), seems to owe its high frequency to yet another cause.

In 1965, Danks et al. ${ }^{2}$, working in Melbourne, reported indications of increased fertility associated with CF. Grandparents of patients, unaware of their carrie status, were found to produce on average 4.75 live offspring, of which 3.42 themselves reproduced, whereas matched control couples produced only 4.13 offspring of which 3.30 had children. This finding was confirmed by Knudson et al. ${ }^{3}$, who found that grandparents of Californian patients had produced on average 4.34 children, compared with the 3.43 of controls, 3.86 and 3.02 respectively surviving to adulthood. Danks et al. also recorded a striking excess of males (1.54:1) among sibships containing CF patients.

These analyses provide no indication whether the effects of CF on fertility and sex ratio operate through male or female parents, but my colleagues and I found that the families of blood-related uncles of British CF patients, half of whom should be carriers, averaged 2.78 children, while aunts' families, averaged 2.19 , and unrelated, matched controls 2.35. Although these differences are not statistically significant, uncles were the only group to exceed their originally intended family size and not want more children. No children in any group had CF. The ratio of male to female children in uncles' families was 1.78 , while that in aunts' was 1.19 and in controls was 1.00 , representing a significant excess of boys in uncles' families.

Taken together these data indicate that the CF allele increases the fertility of men who carry just a single copy, but this relates to the production of male offspring only. Knudson et al. calculated the rate of increase of the $\mathrm{CF}$ allele as around 0.8 per 10,000 per generation, but their calculations do not include the contributory effect of sex ratio, which ensures overrepresentation of the more fertile carrier males in the next generation. In the modern world we must add to this the contribution of CF homozygotes who can now survive to maturity.

The CF allele arose perhaps 23 generations ago $^{3}$ and has been increasing in frequency ever since. At present about one in every 25 white people are carriers. We can expect this proportion to be very much larger in future generations.

Dorian J. Pritchard

Department of Human Genetics,

University of Newcastle upon Tyne, Newcastle upon Tyne NE2 4AA, UK

1. Rotter, J.I. \& Diamond, J.M. Nature 329, 289-290 (1987)

2. Danks, DM Allan, J \& Anderson, C.M. Ann hum. Genet., Lond. 28, 323-356 (1965).

Knudson, A.G. Jr, Wayne, L. \& Hallett, W.Y. Am. J. hum Genet. 19, 388-392 (1967).

4. Pritchard, D.J., Hickman, G.R. \& Nelson, R. Archs Dis. Childh. 58, 290-293 (1983)

\section{Cross-talk between PKC and cyclic AMP pathways}

SIR-In a recent letter to Nature, Yoshimasa et al. ${ }^{1}$ show that on exposure of frog erythrocytes to phorbol ester, phosphate $\left({ }^{32} \mathrm{P}\right)$ is incorporated into the catalytic unit of adenylate cyclase, and there is a twofold increase in cyclase activity of detergent-extracted cell membranes. In a separate experiment, the authors show that phorbol-ester-activated protein kinase $\mathrm{C}(\mathrm{PKC})$ can induce the phosphorylation of bovine brain adenylate cyclase. They conclude that kinase $C$ can activate the cyclic AMP pathway by phosphorylation of the catalytic unit of adenylate cyclase. The authors do not, however, present any quantitative relationship between the extent of adenylate cyclase activation and that of enzyme phosphorylation in their experiments. It is likely that the yield of adenylate cyclase solubilization is higher in the phorbol-ester-treated membranes and therefore that higher activity is observed in the detergent extract. The authors also do not show that 